\title{
Mind and Body, Form and Content: How not to do Petitio Principii Analysis* Louise Cummings
}

\begin{abstract}
Few theoretical insights have emerged from the extensive literature discussions of petitio principii argument. In particular, the pattern of petitio analysis has largely been one of movement between the two sides of a dichotomy, that of form and content. In this paper, I trace the basis of this dichotomy to a dualist conception of mind and world. I argue for the rejection of the form/content dichotomy on the ground that its dualist presuppositions generate a reductionist analysis of certain concepts which are central to the analysis of petitio argument. I contend, for example, that no syntactic relation can assimilate within its analysis the essentially holistic nature of a notion like justification. In this regard, I expound a form of dialectical criticism which has been frequently employed in the philosophical arguments of Hilary Putnam. Here the focus of analysis is upon the way in which the proponent of a position proceeds to explain or argue for his/her own particular theses. My conclusion points to the use of such dialectic within future analyses of petitio principii.
\end{abstract}

In recent years, Putnam has exhibited a philosophical preoccupation with issues of unintelligibility, such as they relate to traditional problems in philosophy-reference, knowledge of other minds, etc. That there is a 'problem' of reference to which a 'solution' must be found is, according to Putnam, the manifestation of a deep metaphysical impulse within us. This impulse has resulted in unintelligible questions and mistaken inquiries in all the major disciplines of philosophy, including inquiry into the informal fallacies.

Putnam's project is not one of scepticism, but is instead an attempt to recapture a historical moment in our thinking, one which is prior to the

\footnotetext{
* This paper was written while the author was a Visiting Fellow affiliated with the Department of Philosophy at Harvard University. The author wishes to acknowledge her indebtedness to Hilary Putnam, Harvard University, for discussion of a number of the issues addressed in this paper. The author is also grateful to a referee of this journal for comments on an earlier version of this paper.
} 
onset of scientism (the form of scientism that I am concerned to examine in the present context is that of scientific reductionism). This he achieves through a process of dialectic-an examination of the presuppositions that inform opposing philosophical positions with a view to revealing the unintelligible nature of those presuppositions. In this way, Putnam is concerned to examine the unintelligibility of the dualist conception of mind, an unintelligibility which extends to the project of causal theories of reference. This unintelligibility is revealed through an examination of the causalist's theoretical claim ('reference is a causal relation') in conjunction with the wider explanatory discourse of which it is a part. The upshot of each dialectical analysis is a greater appreciation both of what constitutes a problem in philosophy and the shape and depth of each of these problems.

I want to suggest that a similar scientism pervades the ongoing controversies of fallacy theory. The manifestations of this scientism include a reliance on dichotomies (e.g. form and content) and the imposition of unintelligible demands, such as the frequently expressed claim that fallacy inquiry must achieve a theory of fallacies. A wideranging dialectical examination of fallacy debates is as timely as that urged by Putnam in disputes between realists and anti-realists. Indeed, a precedent for the form that this examination should take can be found in Putnam's dialectical criticisms of controversies of just this type: 'the aim which I have in mind is to break the strangle hold which a number of dichotomies appear to have on the thinking of both philosophers and laymen' (Putnam 1981, p. ix).

The issues that Putnam has addressed in this regard are extensive and yet a discussion, such as that which will follow, requires that I restrict the degree to which they can be directly examined. Accordingly, I begin with a statement of aim: a case is presented for the abandonment of the form/content dichotomy in the analysis of petitio principii argument. I describe how the basis of this dichotomy lies in a certain picture we have of the relationship between mind and world. A model for the criticism of this dichotorny is provided by an examination of Putnam's challenge to 
the causal theorist of reference. Following Putnam, I grant the causal theorist of reference the only type of explanation available to him on his account (explanation in terms of physicalistic/naturalistic relations) and then proceed to demonstrate how the causalist fails to achieve even the semblance of an explanation of reference-the causal theorist fails to explain how one particular model of the language becomes the relation of reference. This case, in addition to serving as an example of the type of argumentative strategy employed by Putnam, has as its counterpart in fallacy discussions the reductionist analysis of notions like justification in formal (syntactic) terms. I present a justification of the non-questionbegging status of a selected argument with a view to demonstrating the necessarily holistic nature of this pattern of justification. I further contend that no formalist analysis of the justification pattern of petitio argument can assimilate within its analysis the various normative and epistemic factors which properly constitute justification. Moreover, this situation is not improved in any way through the introduction of extraformalist analysis, given the way in which such an analysis is pursued in this context. I avoid an exposition of unintelligibility and of the pervasive influence of Wittgenstein on Putnam's thinking in this area. These features, while important within any detailed examination of Putnam's dialectical method, are of only indirect relevance to the more limited aim of the present context.

In his Dewey Lectures, Putnam (1994a) argues:

Early modern realism's philosophy of mind was an attempt to save some room for our everyday descriptions while fully accepting [the idea that our everyday descriptions cannot possibly apply to the things 'as they are in themselves']. According to this new philosophy of mind, our 'experience' is entirely a matter taking place within the mind (or within the brain), within, that is to say, a realm conceived of as 'inside', a realm where there are certainly no tables and chairs or cabbages or kings, a realm so disjoint from what came to be called the 
'external' world that (as Berkeley insisted) it makes no sense to speak of any experience as resembling what the experience is 'of'. Nevertheless, according to those philosophers who were not willing to follow Berkeley into idealism, 'external' things are the causes of our 'inner' experiences, and, while the person on the street is mistaken in thinking that he or she 'directly perceives' those things, still we 'indirectly perceive' them, in the sense of having experiences caused by them. Moreover, even color and warmth and the other 'secondary qualities' (as they came to be called) can be granted a derivative sort of reality-they do not exist as 'intrinsic properties' of the things 'in themselves', but they exist as 'relational properties', as dispositions to affect our minds (or brains) in certain ways (pp. 468-69).

In the above passage Putnam describes a type of philosophical 'solution' to the 'problem' of explaining the relationship of perceptual experiences to the physical world. ${ }^{l}$ Although seventeenth century in origin, this same 'solution' effectively exhausts the type of explanation that is traded within present-day philosophical accounts of intentionality. For while it is generally held that we can explain our perceptual interaction with the world using some suitably formulated causal mechanism, a similar mechanism is presumed to operate within our talk of thoughts referring to features of reality. ${ }^{2}$ Moreover, as part of these accounts it is argued that these causal relations (1) bridge the gulf brought about by the dualist's dichotomy of the mental and the physical (a gulf over which our conceptual powers cannot extend) and (2) secure a type of objectivity, in that both perceptual experience and the referential capacity of language

1 In proposing a return to an Aristotelian conception of the mind and its relationship to the world, Nussbaum and Putnam, in 'Changing Aristotle's Mind' (Words and Life), reject the view that there is any 'problem' to which we must find a 'solution': 'As Aristotelians we do not discover something behind something else, a hidden reality behind the complex unity that we see and are. We find what we are in the appearances. And Aristotle tells us that if we attend properly to the appearances the dualist's questions never even get going' (1994b, p. 55).

2 Putmam examines the proposals of a number of causal theorists in relation to reference in 'Realisn without Absolutes' in Words and Life. 
are not the products of some fanciful creation on our part, but are ultimately 'caused' by an external world. Indeed, it is by virtue of these causal relations that we can assign content to our thoughts and perceptual experiences-outside of these relations, thoughts and experiences are taken to exhibit syntactic structure only.

I want to examine this syntactic interface of perception and conception, with a view to understanding the type of criticism that will be developed against the form/content dichotomy. Putnam describes the varied nature of these interfaces as follows:

In the tradition, these 'interfaces' ... were originally thought of as mental ... It is not, however, essential to an interface conception of either perception or conception that the interface be mental-in materialist versions, the interface can be a brain process or brain state. In Quine's version of the interface conception of perception, it is nerve endings on the surface of my body that play the role of the interface. In the case of conception, the interface has recently been conceived of as consisting of 'marks and noises' (Rorty); although the interface is not literally 'inside' us on this Rortian conception, it turns out to generate the same problematic 'gap' between thought and the world. (There is also a version-Fodor's-in which the interface is sentences, but not sentences in a public language-marks and noises-but in a language 'inside' our brains, 'mentalese'. This is a kind of combination of the linguistic conception of the interface with the conception of the interface as 'inside the head'.) (Unpublished lecture notes).

Notwithstanding differences in detail, each of these interfaces generates 'the same problematic "gap" between thought and the world'. Putnam, following John McDowell, describes reductionism and eliminativism ${ }^{3}$ (the

3 A different tendency is exemplified by the eliminativist views of thinkers like Richard Rorty, Paul and Patricia Churchland, Stephen Stich and, to some degree, W. V. Quine. Rorty, like Putnau, rejects the central tenet of metaphysical realism, that our mental representations are in correspondence with a mind-independent reality. However, the 
two most important trends in the philosophy of mind) as attempts to bridge just such a 'gap' between the dualist's conception of the mental and the physical. Proponents of the former type of reductionist analysis typically explain intentionality using a range of scientific languages in addition to that of physics: 'Reductionism, with respect to a class of assertions (e.g. assertions about mental events) is the view that assertions in that class are "made true" by facts which are outside of that class' (Putnam 1981, p. 56). An example frequently discussed in this regard is one in which thoughts are 'made true' (given content) by physical facts. 'For another example, the view of Bishop Berkeley that all there "really is" is minds and their sensations is reductionist, for it holds that sentences about tables and chairs and other ordinary "material objects" are actually made true by facts about sensations' (1981, p. 56). A third form of reductionist analysis, this time relating not to truth but to rationality, is that of cultural relativism: '... the cultural relativist's paradigm is a soft science: anthropology, or linguistics, or psychology, or history, as the case may be. That reason is whatever the norms of the local culture determine it to be is a reductionist view inspired by the social sciences, including history' (Putnam 1983, p. 235).

I want to argue, as indeed Putnam has argued, that the common strategy of these approaches is one which is unintelligible in nature. In specific terms, my claim is that no coherent explanation of the 'facts of language'-for example, that we often assert 'There is a castle in view' just when there is a castle in view and not when an igloo is in view-can proceed in the essentially non-intentional manner typical of the analyses described above. In this way, consider the following description by

failure of metaphysical realism holds a fundamentally different significance for these two writers. Putnam's response is to question the dualism behind the metaphysical realist picture, whereas for Rorty the very notion of representation should be abandoned: '.. his [Rorty's] entire attack on traditional philosophy is mounted on the basis that the nature of reason and representation are non-problems, because the only kind of truth it makes sense to seek is to convince one's cultural peers' (Putnam 1983, p. 235). In fact, Rorty has moved from a relativist to a deconstructionist position. 
Putnam of one consequence of the decision to describe reference in terms of non-intentional relations:

... there are infinitely many admissible models of our language, i.e., infinitely many models which satisfy all operational and theoretical constraints. If the entities that these models consist of are thought of as mind-independent discourse-independent entities, then the claim that just one of these models is the unique 'intended' model becomes utterly mysterious. Each of these models corresponds to a reference relation. So there are infinitely many admissible reference relations, $R_{1}, R_{2}, R_{3}, \ldots$ Someone who believes that just one of these, say $R_{17}$, really is the unique real reference relation, the reference relation, believes that the word 'reference' is attached to $R_{17}$ (and not to $R_{1}, R_{2}$, ...) with metaphysical glue. (1983, p. 295)

In the above passage, Putnam is describing a 'permutation' argument similar to that first discussed by Quine in Word and Object. The outcome of Putnam's version of this argument is that each sentence in the language can be reinterpreted in such a way that while the truth-values of whole sentences remain unchanged, the reference relations of their component terms have been extensively altered, to the degree where 'castle' can refer to motorway in one interpretation of the language, to hospital in a second interpretation, to the planet Saturn in a third interpretation, etc. Quine's response to this indeterminacy in our own language is to 'choose as our manual of translation the identity transformation, thus taking the whole language at face value' and he has it in mind that 'Reference is then explicated in disquotational paradigms analogous to Tarski's truth paradigm' (1990, p. 52). A different response to this indeterminacy is given by Michael Devitt (1984). For Devitt, the true relation of reference is itself a causal connection which, for the purposes of the present analysis, is exemplified by the relation $R_{17}$ above. A more recent account, that of Jerry Fodor (1990), appeals to counterfactuals to explain reference. Fodor's counterfactuals express an asymmetrical dependence between causal statements. In this way, the 
referent of 'cat' is arrived at through a counterfactual of the form 'If cats didn't cause "cat" tokenings, then ... (cat pictures, cat statues, the sound "meow", and so on) wouldn't cause “cat" tokenings either' (Putnam 1992, p. 38).

When Devitt discusses causal relation it is with an explanatory role in mind:

So his [the realist's] answer may include a sentence roughly like

Term $\mathrm{x}$ is causally related in way A to object $\mathrm{y}$ and to nothing else as an explanation of another sentence

$x$ refers to $y$ and to nothing else.

In such circumstances he will regard the reference of $x$ as determinate. (1984, p. 189)

Again:

We could have foretold that we would be able to find some causal relation between the entities, because causal relations are ubiquitous. We need to see the one we have picked out as explanatorily special. $(1984$, p. 87)

However, the causal theorist lacks the option of selecting a causal relation which is 'explanatorily special'. To see this, we need to consider exactly what range of notions is involved in the selection of an 'explanatorily special' causal relation. Clearly, such a selection presupposes notions of appropriateness, notions which are normative in nature-after all, the relation which is explanatorily special is also the most appropriate candidate for the relation of reference. Moreover, appropriateness exists as part of a larger web of normative and epistemic notions. A causal relation is appropriate when it satisfies the explanatory function it is called upon to serve. Satisfaction presupposes notions of adequacy, notions which must be in place in order to assess whether a particular purpose, that of explanation, has been fulfilled. 
Now, it is just these normative and epistemic considerations which are unavailable to the causal theorist. $\mathrm{He}$ is pursuing a reductionist analysis-an account of the intentional from within the non-intentionalan essential feature of which is its rejection of all things normative. Putnam's criticism thus turns on the causal theorist's failure to provide any intelligible explanation of reference. The decisive point in his challenge to the causalist comes when he applies the causal theorist's claims to a statement of the causal theorist's own position. For as Putnam contends, if reference is (explained by) a causal relation, then at the very least a causal relation should be able to account for the referential nature of that fact. However, we have just seen the Utopian nature of such a demand-no causal relation that is acceptable to the causalist can assume the essentially holistic character of the notion of explanation. Yet causal theories must achieve exactly this much if they are to continue in their role as an explanation of reference. It emerges that the only option available to the causalist is to dogmatically assert that one particular model of the language-say $\mathrm{R}_{17}$-just is the relation of reference. In doing so, however, we have not explained why $\mathrm{R}_{17}$ is the relation of reference so much as we have simply stated that such is the case (Putnam 1983).

It is worth examining further Putnam's challenge to the causal theorist. I described above how a decisive point in Putnam's criticism of the causalist was reached when the causalist was required to explain how the statement 'reference is a causal relation' referred. This point was described as decisive because it signalled a self-refutation from which the causalist had no route of escape-unless, of course, he was prepared to abandon certain central features of his account, such as the claim that causal relation is an explanation of reference. The form of this selfrefutation is that in order to explain the reference of the claim 'reference is a causal relation', the causalist must appeal to a notion of reference wider than that of causal relation. In this way, reference cannot be a causal relation. Hence, it is false that reference is a causal relation. 
Self-refutation arguments of just this type form a prominent part of Putnam's dialectical strategy. A type of activity, that of explanation, has been central to the self-refutation argument of the present case. In fact, in each self-refutation argument employed by Putnam a theoretical claim is undermined by a proponent explaining or justifying it (see below) or even simply saying or thinking it. The significance of these self-refutation arguments stems from what they are able to tell us about notions such as reference. It was described above how causal relations failed as an explanation of reference, a failure which was attributed to the nonintentional nature of those relations. I now want to make the stronger claim that every attempt to account for reference in this non-intentional way is doomed to failure, given that reference presupposes intentionality. This conclusion turns on a particular understanding of language 'use', one which Putnam attributes to the later Wittgenstein, in which to describe the words in a language game (think of reference as belonging to just such a language game) requires that we employ the words within that same game: 'If one wants to talk of the use of the sentence "There is a coffee table in front of me", one has to talk about seeing and feeling coffee tables, among other things. In short, one has to mention perceiving coffee tables' (Putnam 1994b, p. 283). In the same way, to proceed to discuss how the sentences of our language can be about anything is to already have a mastery of a vast range of notions, including the notion of reference. Before leaving these introductory remarks to examine how the considerations adduced within them relate to the main theme of this discussion, the form/content dichotomy in petitio principii analysis, I examine a criticism of the view that I am proposing.

Central to Putnam's criticism of causal theories of reference is his claim that a causal relation fails to account for the reference of the causalist's theoretical claim, that reference is explained by a causal relation. It may reasonably be objected that Putnam's criticism of causal theories of reference and my criticism, to follow, of a formal approach to the study of petitio principii-I will argue subsequently that no formal (syntactic) relation of justification can justify the formal theorist's claim 
that the justification relation of petitio principii is a formal (syntactic) relation-conflate what are, in effect, two quite different notions of reference and of justification respectively. In this way, it may be argued that by intending that a causal relation of reference serve as an explanation of the reference of the causalist's theoretical claim, Putnam is engaging in a level confusion between the reference of terms within the causalist's theory and the reference of the causalist's theory itself. (Similarly, it may be argued that in the analysis of petitio principii to follow, I am engaging in a level confusion, this time a confusion between justification within an argument and justification of a particular view-a formalist view-of the justification relation of an argument (in the case to follow, of petitio argument.) It may also be argued that the satisfaction of the former type of reference and of justification-the reference of terms and the justification relation within an argument-is not conditional on the prior satisfaction of the latter type of reference and of justification respectively - the reference of the causal theory itself and the justification of a particular view of the justification relation of argument. Such an objection is consistent with Van Cleve's views both of reference and of epistemic justification. In relation to reference, Van Cleve subscribes to semantic supervenience, 'the thesis that semantic facts supervene on nonsemantic facts' (1992, p. 344). These nonsemantic facts, Van Cleve argues, while they give rise to reference, are not thernselves subject to any demand concerning their own reference. So it is that Van Cleve, while he himself holds 'no brief for the causal theory' (p. 349), is quick to challenge Putnam's rejection of the view of Hartry Field, a rejection to the effect that a naturalistic (possibly a causal) relation cannot be, as Field claims it is, the relation of reference, on the grounds that a naturalistic (causal) relation can be shown not to determinately refer:

If semantic phenomena ... are supervenient on natural phenomena, then there must be at least one true principle satisfying Field's schema-a causal principle, as it might be, but if not that, some other principle specifying the natural basis for reference. 
Let us suppose, then, that the following is a true generation principle in semantics ...: if $\mathrm{x}$ bears $\mathrm{R}$ to $\mathrm{y}$, then $\mathrm{x}$ refers to $\mathrm{y}$. Nothing more is necessary; ... Contrary to what Putnam repeatedly insists upon, we do not have to be able to 'single out' one relation as the intended referent of ' $R$ ' before the causal theory (or the R-theory) can do its job. We can do the singling out later ... but we need not do it as a precondition of the successful working of the theory. One might put the point this way: as knowledge makers need not be known, so reference makers need not be referred to (Van Cleve 1992, p. 351).

Van Cleve views as unnecessary Putnam's demand for reference in the case of $\mathrm{R}$ itself. A similar claim characterises Van Cleve's account of epistemic justification-as knowledge makers, 'epistemic principles need not be known in order for knowledge to arise in accordance with them' $(1979$, p. 79$)$. The question now is whether or not the criticism of causal accounts of reference pursued by Putnam and the criticism of a formal approach to the study of petitio principii that I will subsequently pursue can evade a critical response of the type advanced by Van Cleve.

Van Cleve cites the following criticisms by Putnam of the causal theory of reference ('MMS' and 'RTH' stand for, respectively, Meaning and the Moral Sciences and Reason, Truth and History):

A causal theory of reference would not help, "for how "causes" can uniquely refer is as much of a puzzle as how "cat" can, on the metaphysical realist picture' (MMS, p. 126); 'the reference of " $x$ bears $\mathrm{R}$ to $\mathrm{y}$ " is itself indeterminate' (RTH, p. 45); 'it is a puzzle how we could learn to express what Field wants us to say' (RTH, p. 46). (Van Cleve 1992, p. 349)

These criticisms, Van Cleve claims, constitute a "just more theory" objection' (p. 349) on the part of Putnam. I want to argue that Putnam's criticism of causal theories of reference is more subtle than Van Cleve's characterisation of Putnam's criticism suggests. It will be recalled that when Devitt advances his causal theory of reference, he does so in the expectation that such a theory will serve as an explanation of reference. 
Now, Devitt's view is not unique in this regard. For it is the case that explanation is a central notion in all causalist accounts of reference. To understand why this is so, one need only consider the fact that causal theorists pursue an account of reference from within the perspective of metaphysical realism. From within this perspective, causal theorists, as a subgroup of metaphysical realists more generally, set about the establishment of the following chain of explanation. Their aim is to explain the success of science in terms of the reference of the theories of science to subsets of the totality of all objects. Their reductionism, particularly their predilection for physicalistic description, leads them in turn to pursue an explanation of reference in terms of a causal relation. When Putnam criticises this causal relation, it is for the reason that it fails to perform any intelligible explanatory role in relation to reference. In the first instance, the focus of Putnam's criticism is an aspect of the causalist's rational practice, that of explanation, and not an aspect of his theoretical account, as Van Cleve is suggesting is the case. It is this practice which subsequently renders the causalist's theoretical claim, that reference is explained by a causal relation, unintelligible. An understanding of how this is achieved takes us to the very core of Putnam's dialectical criticism of causal theories of reference.

I described earlier something of the holistic character of the notion of explanation-various normative and epistemic concepts were shown to be inextricably connected to this notion. I now want to argue that these concepts constitute a precondition on the very possibility of explanation, in much the same way that the laws of logic for Kant are constitutive of the possibility of thought. Where these prior concepts are absent, what emerges is not a different kind of explanation, but rather no explanation at all. Connected to the impossibility of explanation in the absence of prior normative and epistemic concepts is the unintelligibility of explanation in the absence of these concepts-prior normative and epistemic concepts confer sense on the notion of explanation. Now, the proponent of a causal explanatory relation of reference-this is, in effect, what the causal theorist is proposing through his claim that a causal relation explains 
reference-finds himself in the position of denying the existence of prior normative and epistemic concepts in his account of reference-no causal relation can assimilate these normative and epistemic concepts within its analysis. However, in so denying the existence of these prior concepts, the causalist is effectively denying both the possibility and the intelligibility of an explanation of the reference of terms within the causalist's theory and of an explanation of the reference of the causalist's theory itself. Of course, the impossibility of this latter type of explanation-explanation of the reference of the causal theory itselfmight well be taken to indicate that while a causal theory can give rise to reference, this theory cannot itself be subject to any demand concerning its own reference. (Van Cleve's claim, it should be noted, is that while a causal theory (or an epistemic principle in justification) need not refer (need not be known), just such a theory can refer (just such an epistemic principle can be known).) Such a response, however, still assumes that there is a causal theory, a causal theory the reference of which cannot be explained. However, on the view that I am proposing, if an explanation of the reference of causal theories is not possible, then causal theories themselves are not possible--the concepts which make these theories possible, the normative and epistemic concepts which are integral to the notion of explanation, are absent in the case where an explanation of the reference of these theories is not possible (owing, of course, to the causal framework within which such an explanation is pursued).

It thus emerges that the charge of level confusion against Putnam, and against my account of petitio principii to follow, finds no target. What initially appears to be a point about two different types of reference-the reference of terms which are subsumed by a causal theory of reference and the reference of a causal theory itself-is more accurately a point about certain preconditions for reference, preconditions which hold equally for all instances of this notion. I have identified certain normative and epistemic concepts as forming a precondition on the very possibility and intelligibility of reference. I have also argued that the causal theorist's account of reference, in lacking any 
sort of 'conceptual space' for these normative and epistemic concepts, is, in the final analysis, impossible and unintelligible. Of course, none of what I have said is intended as a rejection of Van Cleve's characterisation of Putnam's early criticisms of causal theories of reference. But I do think that Putnam's recent, and indeed not so recent, view of causal theories of reference is more likely to frame the problem with these theories as being one of their unintelligibility, not as being one of the indeterminacy of any causal relation advanced by the causalist as the relation of reference.

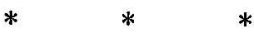

The following proposals of Woods and Hull are typical of the ongoing dialectic in the analysis of petitio principii ${ }^{4}$ :

A further advantage of this sort of formal approach is that it demonstrates that, and the extent to which, possession or lack of target-properties (e.g. circularity) is not a matter of parochial semantic status, and not a matter of parochial contextual and pragmatic features. (Woods 1980, p. 58)

The fallacy of reasoning in vicious circles does not belong to this class of fallacies [formal fallacies]. Instead it is an example of what logicians call a material fallacy. In diagnosing material fallacies both content and

4 Of all the informal fallacies, petitio principii is the fallacy which has been most extensively discussed in the literature. Johnson and Blair (1985) describe how 'Over the past five years researchers have been refining the accounts of the informal fallacies. Begging the question continues to be a preoccupation ...' (p. 186). The five year period to which Johnson and Blair refer is from 1978 to 1983 . This same preoccupation is again evident in Schmidt's (1987) bibliography of the fallacies. Begging the question accounts for 28 of the entries, ad hominem 17 , vagueness 7 , genetic fallacy 7 , composition and division 5 , ad baculum 5 , ad ignorantiam 3, ad populum 3, ad verecundiam 3, ignoratio elenchi 2, many questions 2 , ambiguity 2, ad misericordiam 1, gambler's fallacy 1, and non causa pro causa 1. A similar distribution is to be found in Hansen's (1990) informal logic bibliography-begging the question (31) is second only to the category 'all fallacies other than the 'ad' fallacies and begging the question' (40). Ad hominem and tu quoque arguments account for 24 of Hansen's entries, with ad verecundiam 10, and 'ad' fallacies other than ad hominem and ad verecundiam 13 . 
the use to which the argument is being put play central roles. (Hull 1967, p. 177)

Here Woods and Hull are representative of two frequently encountered approaches to the analysis of petitio, the one formalistic and the other extra-formalistic ${ }^{5}$ in nature. Notwithstanding differences in emphasis and terminology, it is generally accepted that the premises of an argument function by providing some degree of supportive warrant for the conclusion. In this regard, arguments have been variously described as committed to a principle of 'evidential priority', in which the premises are prior to, or better known than, the conclusion. ${ }^{6}$ This principle, while characteristic of most types of argument, is clearly violated in petitio principii reasoning-in this case the premises cannot be evidentially prior to the conclusion, since a proposition identical to, and hence as unknown as, that conclusion is contained within the premise-set ${ }^{7}$. It is

5 It could, of course, be argued that formal theories have been constructed of the very notions that I am here describing as 'extra-formalistic', e.g. Katz's theory of meaning. (Putnam has criticised such theories for failing to account for any philosophically significant notion. In relation to Block's Conceptual Role Semantics, he argues: 'I have remarked a number of times that to identify meaning with "conceptual role" would amount to a total change of topic, and not to an account of meaning' (1988, p. 53).) Through use of 'extraformalistic' I intend only to convey a sense of levels of linguistic organisation distinct from that of sentence structure.

6 Walton and Batten (1984) discuss evidential priority in relation to petitio argument in the following way: "The assumption is that the evidentiary wellknownness of A, in order to make $A$ of utility as a premiss, must be prior to that of $B$. Once the deduction is granted however, the value of $B$ should be adjusted upwards to a plausibility value equal to (and not greater than) A. Once A has been so utilised as a premiss for B however, B could never be used as a premiss in an argument that has $A$ as a conclusion. Reason: to be useful as a premiss, the value of $B$ must be greater than that of $A$. But as was just shown above, the value of $B$ should not be greater than that of $A$, if $A$ has been used as a premiss for $B$ in $a$ previous deduction. Thus arguing in a circle, from $A$ to $B$, and then subsequently from $B$ to A, violates some requirement of evidential priority' (p. 154).

7 The particular conception of petitio presented here is discussed by Woods and Walton (1982) in terms of two distinctions: a dependency versus an equivalence conception of the fallacy and an epistemic as opposed to a game-theoretic model of analysis. While the account in the text is most accurately represented by the Woods-Walton descriptions of the equivalence conception and the epistemic model, these authors are at pains to emphasise what they take to be the equivalence basis of the dependency conception. They describe this as a rejection of their original dependency/equivalence distinction as detailed in Woods and Walton (1975). 
different responses to the question of what factors to include in the identification of this proposition that divide theorists along the formalistic/extra-formalistic lines indicated above.

I want to examine the type of formal approach described above by Woods. At a slightly earlier point in the same article, Woods describes certain prerequisites for the formal treatment of a body of knowledge:

Perhaps it may be assumed that a body of knowledge is non-trivially eligible for formal treatment when (1) the objects of theory enter into interesting systematic interconnections expressible in functional or quasi-functional ways, and (2) such interconnections obtain or not, as the case may be, under semantic suppression of the connected items. (1980, p. 57)

In relation to petitio argument, this formal approach results in "Arguments of the form " $p$, therefore p" ... [the] formal validity [of which] is impeccably reflected in standard first-order logic' (Woods and Walton, 1975, p. 107). My point is not to deny the formal validity of 'p, therefore $\mathrm{p}^{\prime}$, but to indicate that the formal validity of this case rests on the fact that one and the same proposition forms both the premise and the conclusion of the argument. Moreover, sameness in this context is not the sameness of graphemes, the sense in which premise $p$ is the same grapheme as conclusion p, nor is it the sameness of grapheme sequences, the sense in which the grapheme sequence which forms premise $p$ is the same as the grapheme sequence which forms conclusion p. Sameness is used here in relation to propositions, linguistic constructions which admit of truth or falsity through the representation (or lack of representation, as the case may be) of certain states of affairs. Also, sameness presupposes the notion of difference, a difference not of graphemes and of grapheme sequences, but of the states of affairs represented by propositions. The crux of the problem for the formalist is this: what does an ability to distinguish states of affairs come to other than an ability to refer through the use of language? Yet reference is our paradigm semantic notion, not to mention the related notions of 
representation and truth. Clearly, the formal theorist is not able to achieve the suppression of semantics required by his approach.

The objection just outlined is an objection against one type of formal method, that of formal logic. Criticism took the form of the claim that this use of formal techniques, far from operating under the suppression of semantic notions, actually presupposed such notions. One response to this claim could be to emphasise the availability of other formal methods, methods which, it may be argued, are less susceptible to a criticism of this sort. In this way, I now turn to examining a further kind of formal approach, that pursued by certain branches of linguistics. ${ }^{8}$

Linguistic analyses have featured in various ways in discussions of petitio argument. Irving Copi (1972), for example, looks to the orthography for a criterion for the identification of petitio principii, only to reject any orthographic basis for this fallacy:

If one assumes as a premiss for his argument the very conclusion he intends to prove, the fallacy committed is that of petitio principii, or begging the question. If the proposition to be established is formulated in exactly the same words both as premiss and as conclusion, the mistake would be so glaring as to deceive no one. Often, however, two formulations can be sufficiently different to obscure the fact that one and the same proposition occurs both as premiss and conclusion. (p. 83)

In this case, an argument is taken to beg the question when the orthographic form of the conclusion (the sequential arrangement of graphemes) is replicated by one of the premises. Additional formal (syntactic) descriptions can be formulated on the basis of the morphological and grammatical structures of the proposition. The issue then becomes one of assessing the adequacy of orthographic identity, as well as these other syntactic criteria, to the task of petitio analysis.

8 I avoid discussion of particular theories of grammatical syntax, etc., as these are of limited relevance to the more general nature of my account. 
As part of this assessment it will be instructive to examine the formalist's position in the light of the dualist claims that have been raised thus far. It was discussed above how, in the absence of extrinsic causal relations, the philosopher of mind was compelled to describe perceptual experiences and thoughts in terms of a certain intrinsic syntactic structure. The picture presented was one in which our cognitive powers extended as far as a conceptual interface which, while syntactically analysable, was devoid of all content (meaning). Now, it is the specific claim of the formal theorist of petitio principii that a syntactic description of this interface is alone necessary and sufficient for the analysis of petitio. However, such a view fails our clearest understanding of what constitutes petitio reasoning. For it is unexceptional for propositions exhibiting identical syntactic structures to appear as premise and conclusion in a non-question-begging argument: ${ }^{9}$

The castle is larger than the mansion.

The mansion is larger than the cottage.

Therefore, the castle is larger than the cottage.

Here the morphological and grammatical identity of conclusion and premises is insufficient to warrant a description of this argument as question-begging. ${ }^{10}$ Moreover, it emerges that syntactic identity of

9 It may be argued that a question-begging strategy has been adopted in the present context, as certain characterisations of this fallacy have simply been assumed when it is the very character of petitio that is itself at issue. However, such an objection misrepresents the type of approach being developed, with the pattern of justification assuming a spiral as opposed to circular form. Given a preanalytic understanding of petitio, we can proceed to describe an argument in terms of a number of conceptual distinctions. The results of this initial analysis serve to transform in kind our understanding of this fallacy. This enlightened understanding leads in turn to the formulation of further conceptual distinctions and so the process continues, with each stage of justification returning our understanding of petitio to ever increased levels of sophistication and refinement.

10 Using orthographic identity here would produce a somewhat different resultsyntactically distinct propositions would then coexist with our understanding of this argument as non-question-begging. While this would represent a welcome turn of events for the formal theorist of petitio, there is reason to believe that orthographic identity would not be a particularly valuable line of investigation: 'If the proposition to be established is formulated in exactly the same words both as premiss and as conclusion, the mistake would 
premise and conclusion fails as even a necessary condition of petitio argument:

[To] allow every man an unbounded freedom of speech must always be, on the whole, advantageous to the State; for it is highly conducive to the interests of the Community, that each individual should enjoy a liberty perfectly unlimited, of expressing his sentiments. (Whately 1836, p. 223)

Described by Whately (1836) as question-begging, the above argument contains a single premise which is syntactically distinct from the conclusion.

Yet for all this the formalist may respond that a simple multiplication of syntactic criteria will suffice to account for all cases of petitio argument. Here, however, the formalist has misunderstood the nature of the objector's criticism, that no sense can even be given to such syntactically described relations as a premise's being confirmed etc., in the absence, which is so central a tenet of the formal approach, of prior normative and epistemic concepts. The proof of this will be that for every syntactic description intended to coincide with the confirmation of a premise, some wider notion of justification or warrant will be presupposed $^{11}$ by that syntactic description. In this regard, consider

be so glaring as to deceive no one' (Copi 1972, 4th edn). In the final analysis our choice of a criterion of syntactic identity must be one which preserves the idea that the success of this fallacy requires that its assumed premise remain undetected. In keeping with the theme of the text, our notion of what constitutes success for this fallacy is itself part of a wider understanding of petitio argument.

11 The basis of this position can be found in the meaning holism arguments of $\mathrm{W}$. V. Quine. In 'Epistemology Naturalized', Quine explains the problem for the positivists' reductionist approach to meaning as follows: 'How is this inaccessibility [of the empirical meanings of typical statements about the external world] to be explained? Simply on the ground that the experiential implications of a typical statement about bodies are too complex for finite axiomatization, however lengthy? No; I have a different explanation. It is that the typical statement about bodies has no fund of experiential implications it can call its own. A substantial mass of theory, taken together, will commonly have experiential implications; this is how we make verifiable predictions. We may not be able to explain why we arrive at theories which make successful predictions, but we do arrive at such theories' 
again the first example discussed above. There it was argued that syntactic identity was insufficient to warrant a description of this argument as question-begging. It was also indicated, if somewhat briefly, that syntactic identity failed 'our clearest understanding of what constitutes petitio reasoning'. Moreover, in the same context I described this understanding as 'preanalytic', in an attempt to convey what I see as its intuitive basis. Now, given this preanalytic understanding, one might proceed to justify the assessment of the first example as non-questionbegging in the following way: ${ }^{12}$

It appears unproblematic to describe an argument as questionbegging when one of its premises depends in whole or in part upon its conclusion for supportive warrant. Yet this clearly fails to accord with a certain understanding we have of the evidential relationships at work in the first argument above. For we can conceive of how perceptual evidence would confirm the premise 'the castle is larger than the mansion'-we can simply look and see that such is the case (we may, of course, need to perform various measurements, etc.). What we cannot imagine, however, is how simply assuming the truth of the conclusion can contribute in any significant way to a justification of this premise. For the conclusion in conjunction with the second premise (a known premise) is insufficient to justify the proposition 'the castle is larger than the mansion'-this proposition must itself be assumed in order to assimilate the information contained separately in the second premise and conclusion. Yet it is this very proposition which we are attempting to justify. The latter

(1969, p. 79). Given the need for a notion of sameness of meaning in petitio analysis, the convergence of petitio theory on the issues of meaning holism is to be expected.

12 At this basic level of justification the role of notions such as confirmation and evidence has been left deliberately undeveloped ("... we can conceive of how perceptual evidence would confirm the premise ...). In this way, I avoid pre-empting later discussion of the holistic nature of these concepts and, more importantly, I represent this justification as an initial stage in petitio inquiry (see footnote 9). 
pattern of justification is that of a circle, in short the fallacy of begging the question.

Putting aside a clear difference in direction of analysis, ${ }^{18}$ I want to argue that the formal theorist of petitio cannot avail himself of the above justificatory discourse. It is not the case that the concepts of this justification are unacceptable to the formalist-it is no part of his position to reject the idea that we can have evidence for a premise or even that some evidence exceeds other evidence in point of plausibility, relevance, etc. It is rather that no syntactic approach can assimilate within its analysis the essentially holistic nature of this justification. Consider, for example, the interplay of epistemic and normative factors within the above justification. There the confirmation of the premise 'the castle is larger than the mansion' proceeded on the basis of perceptual evidence. I now want to suggest that the selection of such evidence is guided in large part by considerations of relevance, such that measurements of height and the observation of a shooting star are judged to be relevant and irrelevant respectively to the confirmation of this premise. However, relevance is not an isolated notion but one which is further dependent on the concept of meaning-to understand the relevance of evidence $\mathrm{x}$ is to understand the way in which the content of $x$ bears upon the content of a proposition $y$. The dependency of relevance extends still further into an assessment of the purpose for which this evidence is adduced. This is not

13 Of course, the formalist will have a preanalytic understanding of this first example as question-begging and he will produce arguments to that effect during analysis (while I also believe that these arguments will fail to validate his preanalytic understanding, my strategy here is to use the formalist's justificatory practice in defeat of his claims). However, given that we share the same conception of what constitutes petitio reasoning (otherwise we are not even discussing the same subject), a contention, which I consider to be unproblematic, is that similar concepts will emerge in the justifications advanced by each of us in support of our respective positions. This follows from the fact that such justifications can be assessed as displaying positive or negative values along various parameters, e.g. the dependency of a premise on a conclusion. A negative value for a parameter does not imply the absence of that parameter within justificatory discourse: analysis of a non-question-begging argument conld quite reasonably include a description of the premises as receiving supportive warrant which is independent of the conclusion. 
'purpose' in some narrow sense, in which evidence is selected for its relevance to the confirmation of a particular proposition or premise, the sense that we have just discussed. For it is also the case that the larger inquiries of which this confirmation is but one component can also determine what is to constitute relevance within that context. For example, measurements of height might be irrelevant to the confirmation of the premise 'the castle is larger than the mansion', when this confirmation is part of a quantity surveyor's inquiry, an inquiry in which the size of a building is assessed in terms of the area of land that it covers. In fact, the assessment of evidence as relevant to the confirmation of a proposition and as relevant to the wider inquiry of which that confirmation is a part is an assessment which is distinctly normative in nature - in both cases, a statement is being made concerning the adequacy of evidence to particular tasks. Moreover, the factors discussed thus far would feature equally in an analysis of the second example above, where a relation of synonymy (sameness of meaning) between premise and conclusion is intimately connected with the normative assessment of this argument as fallacious. Also, the identification of fallacy presupposes a wider purpose of argument, the proof of a previously unknown proposition, a purpose which has not been fulfilled in the case of this second example. In short, the above justificatory discourse can only be understood in terms of an entire network of concepts, and not some syntactically described component of that network. ${ }^{14}$

Of course, the formalist may concede the holistic nature of the above justificatory discourse, but then deny that such a justification plays any role in petitio argument-after all, his concern is to explain syntactic identity between premise and conclusion, not this holistic notion of justification. But insofar as he is prepared to discuss identity in relation to a premise and a conclusion, he must further countenance a wider context of argument along with all of its attendant concepts. The relation of

14 For further discussion of these issues, see 'Meaning and Mentalism' in Putnam's Representation and Reality. 
identity is at least as problematic for the formal theorist of petitio as was the earlier notion of justification.

Now on the basis of the above discussion, I want to argue that justification is a complex notion, one which owes its possibility to the prior existence of a range of interrelated concepts. This range of concepts, I want to argue further, confers sense on the notion of justification, that is, it is only on the basis of our having some prior understanding of what constitutes notions such as relevance and purpose within the context of argument that we can even claim to make sense of the notion of justification within argument. However, where on the view of argumentative justification that I am proposing, a vast range of concepts not only constitutes the possibility of the notion of justification, but also determines the sense of this notion, the formalist sees either no role or only a superfluous role for these concepts within his account of justification. Justification, the formalist will argue, is a circumscribed concept, and as such is not dependent on other concepts either for its own possibility or for its sense. Given the circumscribed character of justification on the formalist's account of this notion, a syntactic approach, which operates on 'objects of theory' which are 'under semantic suppression' (cf. Woods (1980) above), is ideally suited, according to the formalist, to the analysis of the notion of justification in argument. This last claim of the formalist's is unproblematic indeed-if it is in fact the case that justification can be circumscribed, that is, can be shown to be independent of all other concepts, then a syntactic approach, and a syntactic approach alone, is appropriate to the analysis of the notion of argumentative justification. However, what is problematic, I believe, is the formalist's contention that a circumscribed concept of justification is even possible. In order to demonstrate not only the impossibility of a circumscribed concept of justification, but also the unintelligibility of such a concept-I described earlier that no sense can even be given to such syntactically described relations as a premise's being confirmed etc., in the absence ... of prior normative and epistemic concepts-the justificatory practice of the formalist must be examined. 
Such an examination was undertaken above, in the case of the petitio theorist's attempt to justify his normative assessment of an argument. This normative assessment dealt with the issue of whether an argument was question-begging or non-question-begging in nature, an issue which provided, in effect, an opportunity for the analysis of the justification relation within argument. Now, in attempting to justify his normative assessment of an argument, the petitio theorist was shown to appeal to a range of concepts, concepts which are normally implicit in the justification relation of an argument. These concepts are not unique to a particular theoretical position, but instead underpin the normative and epistemic judgements engaged in by both the formalist and the nonformalist in an attempt to justify the normative assessment of an argument. These concepts, I want to argue, are strictly necessary in nature-they represent a precondition on the very possibility and intelligibility of the notion of justification. Something of the necessary character of these concepts can be demonstrated by examining the impact of their absence on the notion of justification. In the absence of these concepts, a justification of the normative assessment of an argument is not possible-we can only assert that a particular argument is question-begging or is not question-begging (and even this is doubtful, given that assertion, on the view that I am proposing, presupposes the same normative and epistemic concepts that are presupposed by justification) but we cannot say why an argument is question-begging or is not question-begging. Also in the absence of these concepts, no sense can be made of the notion of justification in the case of a normative assessment of an argument-justification is only recognisable as such in the presence of concepts which make it possible to distinguish this notion from closely related notions such as explanation. In short, by describing these concepts as a precondition on the very possibility and intelligibility of the notion of justification, I am claiming that in their absence we are not dealing with a different notion of justification; rather we are not dealing with justification at all. 
In the same way, I want to argue that the formalist's justification of his central theoretical claim-that a syntactic analysis of the justification relation of petitio argument is possible-is a justification which presupposes epistemic and normative concepts, in fact presupposes the same epistemic and normative concepts which were shown above to be presupposed by the relation of justification within an argument (if we are talking about justification at all, this last claim must be true). Yet it is just at this point in the formalist's account, when the formalist comes to a justification of his own theoretical claim, that the self-refuting nature of that account becomes evident. For if, as the formalist is claiming, a syntactic analysis of the justification relation of question-begging argument and, by logical extension, of non-question-begging argument, is possible, then at the very least a syntactic analysis of the justification relation of the argument which is required in order to establish the formalist's theoretical claim, must be possible. However, as the discussion to date is intended to show, just such a syntactic analysis is not possible: through its denial of the necessary priority of epistemic and normative concepts within its analysis, the syntactic approach is effectively denying the very concepts which constitute a precondition on the possibility and the intelligibility of the notion of justification. The formal theorist of justification is faced with a dilemma which is not unlike the dilemma which is faced by the causal theorist of reference: he must either concede the impossibility and the unintelligibility of his central theoretical claim-that a syntactic analysis of the justification relation of questionbegging argument is possible-or he can declare his central theoretical claim to be justified, but in so doing he is making use of a notion of justification which is not available to him from within his syntactic approach. The formal theorist's only route of escape from this dilemma is to forego even the possibility of a syntactic analysis of justification, and to pursue in its place a holistic analysis of this notion, an analysis in which the 'open texture' of justification is emphasised.

I want to summarise at this stage what I am presenting as unacceptable within the formalist's position. The formalist is proposing a 
formal analysis of petitio principii, an analysis in terms of the structural properties of the component propositions of this fallacy. In specific terms, this amounts to the claim that syntactic structures can simply supplant notions like evidence and justification, notions which are central to an understanding of petitio as a type of argumentative failure. It has been my contention that no analysis of intentional notions such as evidence and justification can proceed in the manner envisaged by the formalist. I demonstrated this in the following way. I examined how justificatory discourse, in fact the very justificatory discourse used by the formalist to validate his theoretical claim, appealed to an entire network of concepts and I further suggested that no syntactic relation could both coincide with the 'open texture' of such a justification and comply with the restrictive nature of a syntactic analysis. The critical challenge is again that of a self-refutation ${ }^{15}$-if the justification pattern of petitio argument is a syntactic relation, then a syntactic relation fails as a justification of this fact. In this way, justification cannot be a syntactic relation. Hence, it is false that justification is a syntactic relation. This self-refutation is the direct result of the attempt to pursue an explanation of intentional notions in strictly non-intentional (in this case, syntactic) terms. I have called this project one of reductionism and have indicated that $I$ view it as being fundamentally misconceived, given that an explanation of intentionality must first make use of intentional notions (cf. 'use' in later Wittgenstein). It is with these considerations in mind that I now turn to the claims of the extra-formalist.

For the extra-formalist, content (meaning) emerges as an essential concept in the analysis of petitio argument. As such, the extra-formalist is concerned to explain what he views as the question-begging nature of the second example above in terms of a synonymy relation between premise and conclusion. Within the context of a dualist conception of mind ${ }^{16}-a$

15 Putnam develops a similar self-refutation criticism against logical positivism in 'Two conceptions of rationality' in Reason, Truth and History.

16 Putnam has argued that this particular conception of mind represents a largely uninterrupted line of thought since certain developments in empiricism. For a discussion of 
presupposition of both the extra-formalist's and the formalist's positions-the extra-formalist's notion of content amounts to a claim about the existence of causal links. In this way, it is held that content can be explained in terms of a causal mechanism, one in which various interfaces, themselves syntactically described, are causally dependent on (are 'caused' by) features of reality. 'Causal connection' has already been discussed within the context of Devitt's response to the permutation (model-theoretic) arguments of Putnam. The conclusion to emerge from this discussion was that causal connection failed to 'single out' a unique relation of reference and, a fortiori, failed to address the problem of referential indeterminacy, the resolution of which had been its very raison d'étre. I suggested that the basis of this failure lay in the non-intentional nature of the naturalistic/physicalistic relations which were called upon as a causal explanation of reference. Given his commitment to a causalist form of explanation, the extra-formalist is similarly at a loss to account for his notion of meaning. If he includes within his explanation of meaning any object or state of affairs which stands in a physical relation to a thought or perceptual experience (a causal link is, after all, a type of physical relation), then causes will emerge in the explanation of the content of a thought which are in no intelligible sense part of that thought's meaning. If, on the other hand, the extra-formalist attempts to restrict the causes that he is prepared to countenance in relation to the meaning of a thought, then the very fact that he is able to do so indicates that he must already be in possession of a prior concept of meaning. Then given the intentional nature of his explanation, the extra-formalist can no longer claim that he is pursuing a non-intentional account of meaning.

As further illustration of these factors, consider a situation in which you are preparing an exhibition on English architecture in the Middle Ages. At one stage in your research of this topic, the thought that 'the

what he takes to be the origin of the mind/body problem, see 'How Old Is the Mind?' in Words and Life. 
castle is larger than the mansion' comes to mind. If we were to pursue a causalist explanation of the meaning of this thought, a large number of scenarios-a drawing in a child's picture book, a piece of text in a historical volume, the actual estate of a French nobleman-could enter into this account, and no one of these situations could assume greater significance in this explanation than the others. Yet, as a matter of fact, your only causal interaction in this case is with the historical volume. Of course, it may be argued that only causal relations of the relevant type should feature in an assessment of meaning. However, given previous discussion about the relationship between relevance and meaning, it appears that if we are able to state in what a relevant cause would consist, then meaning has not been explained, but simply presupposed. The difficulty with causalist accounts of meaning is not that there are no links of this nature between our mental experiences and thoughts on the one hand and features of reality on the other, but that there are too many such links and we lack any method of singling out the appropriate causal relation-any method, that is, which does not itself make use of the notion-to-be-explained. ${ }^{17}$

The extra-formalist may respond at this point by changing the locus of his causalist account of meaning. He may argue that by including sense data-the essential feature of which is that they are contained within the mind/brain-in a causalist explanation of meaning, the multiplication of causal states, which vitiated his original claims, could then be avoided. However, given the syntactic nature of these sense data, ${ }^{18}$ it is difficult to see how this particular move avoids any of the problems described above. For it is the case that any sense datum that we would

17 'Two philosophical perspectives' in Reason, Truth and History and 'Realism without Absolutes' in Words and Life address these issues.

18 Traditionally, sense data have been viewed as constituting an unconceptualised interface between the inner processes of mind and the entities of the external world. Their supposed unconceptualised nature encouraged the acceptance of the view that sense data guaranteed the objectivity of the knowledge based upon them. Within the present context, in appealing to sense data, themselves syntactically analysable, to explain meaning, the similarity with the formalist's analysis of meaning and other intentional notions is clear. 
causally countenance with respect to a thought must itself interact with a vast background of linguistic knowledge. In this way, we can affirm 'the castle is larger than the mansion', because a certain arrangement of sense data is observed to occur. Yet such an affirmation is itself dependent on our knowing the significance of these data. As before, meaning is presupposed rather than explained.

I contend that the arguments advanced in the present context indicate the need to abandon the form/content dichotomy in the analysis of petitio principii. Also, I take these same arguments to defeat any position $^{19}$ that has as its basis the dualist conception of mind that has been discussed here in relation to petitio reasoning. As indicated above, it is part of this dualism that our conceptual powers cannot extend as far as objects of reality, that an interface exists between entities of the mind and of the external world. The reductionist, in attempting to bridge the gulf created by this interface, pursues an explanation of intentionality from within a dualistic conception of the physical. In this way, the links extending outwards (to reality) and inwards (to thoughts and beliefs) from the interface are held to be strictly causal (non-intentional) in nature. It has been the purpose of this discussion to demonstrate that it is the non-intentional nature of these causal links and interfaces that ultimately invalidates the claims of both the formalist and the extraformalist. For in order to describe the meaning of a premise or the way in which a premise is justified, we must first make use of intentional notions, in fact the intentional notions of meaning and justification, in the very language that we employ. The indeterminacy ${ }^{20}$ which emerged from the analyses above is the direct result of a failure to recognise this fact. ${ }^{21}$

19 Putnam has recently examined perception and reference in relation to mind/body dualism in 'Realism without Absolutes' and 'The Question of Realism' in Words and Life.

20 In failing to grasp the true source of the indeterminacy to emerge from the permutation arguments of Putnam and Quine-the use of non-intentional discourse to explain intentional notions-- theorists such as Devitt have responded to this indeterminacy in a way which further perpetuates it. Devitt's 'causal connection' response to Putnam simply reintroduces indeterminacy, only this time at the level of the second-order statement that the word 'reference' is causally connected to $R_{17}$ : 'It is not that there aren't various 
In conclusion, I want to sketch briefly what I consider to be the way forward in petitio principii analysis, a way forward which has itself been instrumental in rejecting the form/content dichotomy. In examining issues of form and content in the current discussion, the focus of analysis was upon the type of justification and explanation advanced by the formalist and extra-formalist respectively in defence of their claims. Indeed, the very basis of the rejection of this dichotomy lay in our understanding that a type of justificatory and explanatory failure had occurred, for example, that the only way in which the formalist and the extra-formalist could even begin to make their claims precise required that they make use of the very notions to which they were fundamentally opposed. Now, the true value of this type of dialectical ${ }^{22}$ inquiry consists in the changes that it effects within our understanding of the nature of certain problems, such as, in the present context, in the way in which we view notions like evidence and justification. These different and, I would argue, improved ways of thinking about such concepts could facilitate discussion of related issues, for example, could facilitate discussion of the issue of the conditions under which petitio principii, normally

naturalistic connections between the word 'reference' and $R_{17}$; it is the idea that one of these declares itself to have the honor of making $R_{17}$ be the relation of reference independently from all operational and theoretical constraints that is entirely unintelligible' (Putnam, 1983, p. 296).

21 'Given the lack of any rational connection between the surface irritations and what is outside (or inside) the skin, it is not to be wondered at that language ends up without any determinate reference to reality' (Putnam 1994b, p. 282). ('Surface irritations' refers to stimulations of nerve endings in Quine's model of language.)

22 The dialectical nature of Putnam's investigations is clearly evident. James Conant, in the introduction to Words and Life, describes this particular element in Putnam's thought: 'Some of them [Putnam's essays] begin with a dialectical overview of a philosophical controversy (often in order to try to bring out how the crucial presuppositions are ones which both parties to the dispute share). The proximate goal of these essays therefore is not to attempt to have the last word about a philosophical problem, but rather to give the reader a sense of the shape and the depth of the problem-of how, for example, in a particular philosophical dispute, thesis and counter-thesis bear one another's stamp and how each of the pair comes with its own false bottom, hiding the true dimensions of the problem from view' (p. xiii). It has been a contention of this discussion that the presuppositions shared by both the formalist and the extra-formalist have their bases in a dualist conception of mind. 
considered to be a fallacy of argument, represents an acceptable form of argument. These are issues to which more conventional forms of analysis have been applied with only limited success. To date, this move in the direction of a dialectical approach to the study of fallacies has been limited in extent. However, the first signs of such a move are beginning to emerge (Levi, 1994).

University of Ulster

\section{References}

Copi, I. (1972). Introduction to Logic. 4th edn, New York: MacMillan. Devitt, M. (1984). Realism and Truth. Princeton: Princeton University Press.

Fodor, J. (1990). A Theory of Content. Cambridge, Mass.: MIT Press. Hansen, H. V. (1990). 'An Informal Logic Bibliography'. Informal Logic, vol.12, no.3, pp. 155-84.

Hull, D. L. (1967). 'Certainty and Circularity in Evolutionary Taxonomy'. Evolution, vol. 21, pp. 174-89.

Johnson, R. H. \& Blair, J. A. (1985). 'Informal Logic: The Past Five Years 1978-1983'. American Philosophical Quarterly, vol.22, no.3, pp. 181-96.

Levi, D. S. (1994). 'Begging What is at Issue in the Argument'. Argumentation, vol. 8, pp. 265-82.

Putnam, H. (1978). Meaning and the Moral Sciences. London: Routledge and Kegan Paul.

Putnam, H. (1981). Reason, Truth and History. New York: Cambridge University Press.

Putnam, H. (1983). Realism and Reason, Philosophical Papers, vol. 3. New York: Cambridge University Press.

Putnam, H. (1988). Representation and Reality. Cambridge, Mass.: MIT Press.

Putnam, H. (1992). Renewing Philosophy. Cambridge, Mass.: Harvard University Press. 
Putnam, H. (1994a). 'The Dewey Lectures 1994: Sense, Nonsense, and the Senses: An Inquiry into the Powers of the Human Mind'. Joumal of Philosophy, vol. 91, no. 9, pp. 445-518.

Putnam, H. (1994b). Words and Life. Edited by James Conant. Cambridge, Mass.: Harvard University Press.

Quine, W. V. (1960). Word and Object. Cambridge, Mass.: MIT Press. Quine, W. V. (1969). Ontological Relativity and Other Essays. New York: Columbia University Press.

Quine, W. V. (1990). Pursuit of Truth. Cambridge: Harvard University Press.

Schmidt, M. F. (1987). 'Fallacies: A Bibliography in Process'. Informal Logic, vol.8, no.2, pp. 105-11.

Van Cleve, J. (1979). 'Foundationalism, Epistemic Principles, and the

Cartesian Circle'. The Philosophical Review, vol. 88, no.1, pp. 55-91.

Van Cleve, J. (1992). 'Semantic Supervenience and Referential Indeterminacy'. The Journal of Philosophy, vol. 89, no.7, pp. 344-61. Walton, D. N. \& Batten, L. M. (1984). 'Games, Graphs and Circular Arguments'. Logique et Analyse, vol.106, pp. 133-64.

Whately, R. (1836). Elements of Logic. New York: William Jackson. Woods, J. (1980). 'What Is Informal Logic?'. In J. A. Blair and R. H. Johnson (eds), Informal Logic: The First International Symposium. Inverness, California: Edgepress.

Woods, J. and Walton, D. (1975). 'Petitio Principii'. Synthese, vol. 31, pp. 107-27.

Woods, J. and Walton, D. (1982). 'The Petitio: Aristotle's Five Ways.' Canadian Joumal of Philosophy, vol. 12, no. 1, pp. 77-100. 